University of Nebraska - Lincoln

DigitalCommons@University of Nebraska - Lincoln

Educational Psychology Papers and

Publications

Educational Psychology, Department of

$11-20-2004$

\title{
Consultation With School Personnel
}

Susan M. Sheridan

University of Nebraska-Lincoln, ssheridan2@unl.edu

Richard J. Cowan

University of Nebraska-Lincoln, rcowan1@kent.edu

Follow this and additional works at: https://digitalcommons.unl.edu/edpsychpapers

Part of the Educational Psychology Commons

Sheridan, Susan M. and Cowan, Richard J., "Consultation With School Personnel" (2004). Educational Psychology Papers and Publications. 32.

https://digitalcommons.unl.edu/edpsychpapers/32

This Article is brought to you for free and open access by the Educational Psychology, Department of at DigitalCommons@University of Nebraska - Lincoln. It has been accepted for inclusion in Educational Psychology Papers and Publications by an authorized administrator of DigitalCommons@University of Nebraska - Lincoln. 
Published in Handbook of Pediatric Psychology in School Settings, edited by Ronald T. Brown, Lawrence Erlbaum Associates, Publishers, Mahwah, New Jersey \& London, 2004. Pages 599-616.

Copyright (C) 2004 Lawrence Erlbaum Associates, Inc.

Used by permission. 


\title{
31 \\ Consultation With School Personnel
}

\author{
Susan M. Sheridan \\ Richard J. Cowan \\ University of Nebraska-Lincoln
}

\begin{abstract}
INTRODUCTION
Consultation services in school settings is gaining increased recognition in research, training and practice, and is expanding to include a variety of related professionals as consultants (e.g., special educators, counseling psychologists, community psychologists, speech pathologists; Gutkin \& Curtis, 1999). There also appears to be a trend in increased consultation between medical professionals (e.g., general physicians, pediatricians, psychiatrists) and school personnel. Whereas the term consultation may have broad meanings across educational, medical, and psychological practice, one common feature is that consultation generally consists of two or more people working together to address concerns regarding a third-party client (Sheridan \& Kratochwill, 1991). As applied to school settings, consultation is defined as collaborative problem-solving between a professional consultant (e.g., psychologist, medical expert) and one or more persons (or consultees; e.g., parents, educators) who are responsible for providing some form of educational and/or psychological assistance to a child-client (adapted from Medway, 1979). This definition represents consultation as conceptualized in this chapter.

The purpose of this chapter is to introduce school-based consultation as a viable feature of pediatric and psychological services. The salient features of consultation will be presented, including theoretical foundations, models, and stages. Benefits of consultation, research findings, and considerations for conducting consultation in school settings will also be explored.
\end{abstract}

\section{Models of School-based Consultation}

Three models have been particularly influential within the field of school-based consultation: (1) behavioral consultation (BC; Bergan \& Kratochwill, 1990), (2) mental health consultation (MHC; Caplan, 1970), and (3) organizational consultation (Maher, Illback, \& Zins, 1984). $\mathrm{BC}$, which is based on behavioral theory and applied behavior analysis, has received the most 
empirical and clinical attention in the field (Bramlett \& Murphy, 1998; Sheridan, Welch, \& Orme, 1996). BC is procedurally operationalized through a four-stage, problem-solving model, including problem identification, problem analysis, treatment implementation, and treatment evaluation (see later section). Conjoint behavioral consultation (CBC; Sheridan, Kratochwill, \& Bergan, 1996) is a conceptual and procedural expansion of BC, in which parents are actively and meaningfully involved with school personnel and other service providers throughout the consultation process (e.g., Sheridan, Eagle, Cowan, \& Mickelson, 2001).

Mental health consultation is grounded on psychoanalytic theory-focusing primarily on helping consultees gain insight into how personal feelings and behaviors that may be contributing to the presenting problem(s) (Caplan, 1970)-has been operationalized via two approaches: (1) teacher-centered consultation (primarily emphasizing the teacher's feelings, attitudes, and skills in relation to identified concerns) and (2) child-centered consultation (focusing primarily on specific academic or behavioral concerns related to a child or group of children; adapted from Bramlett \& Murphy, 1998). Organizational consultation is concerned with systems-level change. The primary focus in organizational consultation is on broad-based organizational assessment and intervention, rather than individual child-centered services. Compared with BC and $\mathrm{MHC}$, organizational consultation has received the least amount of empirical and clinical attention within school settings (Bramlett \& Murphy, 1998; Gutkin \& Curtis, 1999).

\section{The Role of Indirect Services and Ecological Theory in Consultation Practice}

In traditional psychological and medical practice, the psychologist or medical expert works directly with the client to problem-solve or provide treatment. Alternatively, in school-based consultation, the psychologist or medical expert works primarily with other professionals or caregivers (i.e., teachers, support staff) and parents who (1) have frequent, direct contact with the child-client (i.e., student); and (2) ultimately implement an applied intervention (i.e., consultees act as treatment agents within the consultation framework). Given their pivotal role in the consultation process, parent and teacher expertise and support are necessary conditions for consultation, and for the child to receive the services he/she needs to achieve success across settings. The indirect service-delivery model operates on the premise of two primary goals: (1) the short-term goal of resolving the student's presenting problem (i.e., a remedial approach) and (2) the long-term goal of improving the consultees' problem-solving skills (i.e., a preventive approach; Bramlett \& Murphy, 1998).

Ecological theory provides a useful conceptual framework for school-based consultation. Ecological theory conceptualizes behavior and development as a "mutual accommodation" between an individual and the individual's environment (Sheridan \& Gutkin, 2001). Bronfenbrenner (1977) maintains that each individual is an inseparable part of a small social system and that an individual's development occurs within the context of four interrelated systems within the greater ecological environment: microsystem, mesosystem, exosystem, and macrosystem. A child's microsystem is defined as the relationship between the child and his/her immediate environment (e.g., home, school). A mesosystem is comprised of the interrelation between the major systems (and settings) in a child's life (e.g., the interaction between home, school, and other treatment settings). In ecological theory, an exosystem is defined as influences from settings in which the child is not directly included, but that affect that child in his/her immediate setting (e.g., a teacher's personal life). Finally, the macrosystem is concerned with the overall cultural and subcultural patterns (e.g., the effects of political influences and societal norms and values on an individual child's life). Consultation is concerned primarily with the mesosystemic patterns and relationships influencing development (Conoley, 1987; Hansen, 1986; Sheridan, Kratochwill, \& Bergan 1996), and focuses analysis and intervention at this level. 
Because parents and teachers have a strong presence in the home and school environments, and because of their expertise about, influence over, and relationship with the child-client, they are the primary consultees (and treatment agents) in school-based consultation. Gutkin and Conoley (1990) refer to the premise of working with parents and teachers to promote behavioral change as The Paradox of School Psychology, stating that, "to serve children effectively school psychologists must first and foremost concentrate their attention and professional expertise on adults" (p. 203). That is, in school-based consultation, the primary focus is working with parents and teachers who ultimately interact with and provide intervention for the child. Alternatively, in traditional psychological practice, direct services with the identified client is the norm, and working with significant others is considered supplementary to one-on-one interactions between the psychologist and client. These considerations have implications for school psychologists, clinical and counseling psychologists, medical experts, and other professionals alike.

Because school-based consultation implies by name the inclusion of teachers, educators, and other school-based personnel, it may be easy to direct limited attention to the significant role parents can play in the consultation process. There are several benefits of working with parents. Parent participation in school-based services and activities is related to increased student achievement, better attendance, better study habits, fewer discipline problems, regular homework habits, greater similarity between the home and school systems, and more positive attitudes toward school (Christenson \& Sheridan, 2001). Furthermore, including parents as resources in educational problem-solving may have benefits for educators faced with demanding schedules and often-limited resources.

Additional benefits of including parents in school-based services are evident. Research has clearly demonstrated the efficacy of models utilizing parents and teachers as joint consultees (Colton \& Sheridan, 1998; Ray \& Watson, 2001; Sheridan, 1997; Sheridan et al., 2001; Weiner, Sheridan, \& Jenson, 1998). Furthermore, continuity among programs across multiple settings, enhanced maintenance and generalization of consultation goals, and constant monitoring of intervention side effects have been noted (Galloway \& Sheridan, 1994; Sheridan, Kratochwill, \& Elliott, 1990). It is the belief of these authors that consultants should strive to include parents in consultation practice whenever possible.

\section{Participant Roles in Consultation}

By definition and design, consultation in school settings and with school personnel requires interdisciplinary communication and partnering. Optimal conditions for such partnerships occur when participants assume close working relationships, wherein all parties have specified and joint rights, roles, and responsibilities (Welch \& Sheridan, 1995).

In school-based consultation, the teacher-professional (consultee) has important roles related to the classroom context and a child's functioning within that context. Teacher consultees are generally responsible for sharing information about the target child, collecting information, contributing ideas for intervention plans, and monitoring effects of the intervention in the natural setting of the classroom (Sheridan \& Kratochwill, 1991). Specifically, teachers can share expertise about a particular classroom within which the target child must function, describe academic/behavioral concerns, report the child's behavioral functioning in school environment, assist in the determination of consultation priorities and goals, collect naturalistic data, implement plan strategies at school, and collect data to ascertain efficacy of the intervention in addressing primary concerns.

Parents of children who are the focus of consultation also have important roles in problemsolving. Parent roles include sharing expertise about the child from historical, developmental, and cross-setting perspectives; describing behavioral, social, and emotional concerns as they present in multiple contexts; and reporting behaviors that occur at home and in other settings. 
Similar to teacher consultees, parents can help determine consultation priorities and goals, collect data in naturalistic settings, implement specific plan strategies at home, and monitor the effectiveness of the intervention plan.

Consultants have unique and essential roles in consultation, particularly when the issues to be discussed present complex or challenging circumstances. They share expertise about unique conditions that are presented (e.g., medical, developmental, psychiatric issues) and their expected effects on the child's functioning. Furthermore, they are generally responsible for guiding the problem-solving process from initial identification of a concern to its resolution or management (Sheridan \& Kratochwill, 1991). They assist consultees to focus on salient issues, explore conditions surrounding a primary concern, form hypotheses about behavioral function, generate alternative intervention options, establish specific and effective plan strategies, and evaluate treatment outcomes. Importantly, they also provide support and assistance throughout the consultation and plan implementation process through formal (e.g., provision of materials and resources, demonstration or training related to interventions) and informal means (e.g., phone calls, visits to the school, offers for assistance).

\section{Relationships Among Participants in Consultation}

Consultation is an interpersonal endeavor. It involves human interaction among individuals in an ongoing relationship. There are certain characteristics of consultative relationships that, when realized, can maximize the success of the team's functioning. These are listed in Table 31.1 and described herein.

The relational status in the consultation interaction is coordinate and interdependent, meaning that participants' roles are complementary, and each member has equal opportunity in the decision-making process. This recognizes the benefits of the unique contributions of each individual, and that expertise is unique and not necessarily identical. Decisions are made when team members collectively identify the most appropriate, effective, and reasonable alternative given the range of possibilities and resources available. There is joint responsibility for the child's success, and for the establishment and maintenance of a cooperative consultation relationship. This is contrasted with a hierarchical relationship in which one party attempts to control or dictate the actions of the others. Most authors now agree that coordinate, coequal status in consultation is most conducive for constructive and successful interactions (Brown, Pryzwansky, \& Schulte, 1995; Gutkin \& Curtis, 1999; Sheridan \& Kratochwill, 1991).

Consistent with the coordinate relational status in consultation is the prerogative of consultees to reject consultants' recommendations. Recognition of this inherent aspect of the process is critical for consultants who enter systems with the intent of imparting expertise and expecting complete acceptance and compliance with intervention requirements. Several variables affect a consultee's willingness to accept an intervention, including features of the

TABLE 31.1

Characteristics of Relationships in Consultation

- Relationships are coordinate and interdependent.

- All participants are active in identifying priorities, exploring options, and making decisions.

- Participation is voluntary.

- Participants have the right to reject suggestions.

- Maintenance of a positive interdisciplinary relationship is a priority.

- The relationship occurs in a context with the child at center. 
school and classroom systems; theoretical orientation of the consultee; skills, knowledge, or materials necessary to implement the intervention; and perceived effectiveness of the treatment plan (Witt, Martens, \& Elliott, 1984). Respect for these unique perspectives and realities is a critical element in the consultation relationship.

The active involvement of all participants is generally considered important in the consultative relationship. This is based on the premise that such involvement will increase ownership and commitment to identifying, analyzing, and resolving concerns. Early research has demonstrated that consultee implementation of interventions developed in consultation is directly related to the degree of consultee involvement in problem-solving (Reinking, Livesay, \& Kohl, 1978).

A primary assumption in consultation relationships is that participants are involved voluntarily. In some circumstances, a consultee (e.g., teacher, school administrator) approaches a consultant (e.g., medical or pediatric specialist) and requests assistance with a particular concern. In other cases, specialists working with a child or family recognize the importance of sharing and obtaining information with and from school personnel. Regardless of the direction of referral, it is imperative that such interactions occur, and that they do so without coercion or undue pressure. It is the experience of these authors that school personnel welcome overtures made by specialists who are working with a specific child or family when they are collegial, constructive, and sensitive to the unique systemic features of schools.

Participant interest in problem-solving is but one essential element to maximize success in consultation. Maintenance of a positive interdisciplinary relationship is also a priority. Effective consultation requires more than simply coming together and sharing ideas and information. To promote benefits to the child in terms of effective cross-system services, identifying and prioritizing ongoing means by which individuals can work together and continue problem-solving on behalf of the child are necessary. Personal needs, goals, and agendas are put aside to allow the needs and goals of the group (i.e., to identify, implement, and evaluate services for the target child) to take precedence. All parties must believe in the worth of the interprofessional relationship, and expend time and energy necessary for its maintenance.

A final consideration is the recognition that consultation relationships occur in a context with the child at center (Christenson \& Sheridan, 2001). Although time may be spent sharing facts and expertise, primary attention is always given to the benefits and outcomes to the childclient. To be successful, interventions or management plans must be developed based on the specific needs and contexts within which the specific child resides. Consultative interventions are useful only to the extent to which they are responsive to needs within the naturalistic context (i.e., within the particular school, classroom, family unit).

\section{OVERARCHING BENEFITS AND GOALS OF CONSULTATION IN SCHOOL SETTINGS}

There are numerous benefits and goals associated with consultation, particularly when practiced across settings in an interdisciplinary fashion. Table 31.2 outlines several benefits to clients and participants in the consultation process. When conducted in school settings, the goals of consultation are threefold: to share information among primary individuals in a child's life, to assist in addressing concerns or problems experienced by the child, and to identify and coordinate multiple services needed by children and families.

\section{Consultation as Information-Sharing}

In consultatitive forms of interaction, individuals with a range of skills, knowledge, and expertise come together to share information relevant to a situation. Ideally, the sharing of information is bidirectional, with pediatric or health-related information shared by appropriate medical 
TABLE 31.2

Benefits of Interdisciplinary Consultation-Based Services

- Improved performance (e.g., behavioral competence, skill development) for targets of consultation (i.e., clients).

- Enhanced communication and coordination among medical/community professionals and educational personnel.

- Continuity in programs and approaches across multiple contexts.

- Shared ownership and commitment to educational goals.

- Increased understanding and conceptualization of the complexities of a child and his/her situation.

- Pooling of resources across home and school increases the: -range and quality of solutions,

-diversity in expertise and resources, and

-integrity of educational programs.

personnel, academic and behavioral information shared by school staff, and developmental and personal information (as appropriate) shared by parents. Sharing information in this manner is beneficial for many reasons. First, it allows for comprehensive and functional data to be communicated among the primary individuals who share responsibility for a child. When questions remain about aspects of the child's functioning, it provides a mechanism by which more data can be collected over distal temporal and contextual bases. In this way, the holistic nature and needs of the child are kept central.

Information-sharing among professionals and parents is also beneficial in that the diversity of expertise and resources available to address target concerns is maximized. By virtue of unique backgrounds, training, and experiences, the various participants in consultation hold differing perspectives and ideas. Pooling such information magnifies the range and quality of services available to a child. No one individual is expert in all knowledge and skill domains necessary to fully support a child with developmental, medical, or learning challenges. In a similar vein, children present their difficulties in unique ways in different settings (i.e., what is demonstrated in a school setting may not be exhibited in a clinic setting and vice versa). Knowledge of the perspectives and skills of the various members may help determine the most appropriate or relevant individual to provide specialized services (Neill, 1997).

Third, information-sharing among pediatric and school professionals enhances the skills, knowledge, and behaviors of all parties (i.e., family members, school personnel, medical personnel, child). For example, characteristics of a child's medical or psychological condition may likely affect his/her academic, social, and/or behavioral functioning at school and home. Information about characteristics of the disorder, behavioral expectancies, medication issues, and necessary precautions is extremely important for all service providers and caregivers to understand. Likewise, school personnel, such as teachers and aides, can share important information about the classroom or school structure, academic or social-behavioral expectations, observations of performance, and changes in behavior or temperament.

Related to sharing relevant information about a child and his/her situation, a fourth benefit of information-sharing is that it increases knowledge about systems. Interdisciplinary consultation recognizes at its core that a child is part of several interrelated systems. Consultation theory posits that these ecological contexts are interlocking, such that events, expectations, and contingencies that occur in one system affect all other systems. Unfortunately, oftentimes these systems do not communicate or interact on behalf of the child, and although perhaps equally interested in the child's welfare, they may often work at cross-purposes, or at least 
inefficiently, with each other. Consultation can improve relationships among change agents, promote continued problem-solving over time, and lend to efficient intervention in the advent of new or related problems.

\section{Consultation as Problem-Solving}

Among the hallmark goals of consultation is the goal to address problems or concerns as they present themselves in specific contexts. By virtue of the diverse expertise available in consultative relationships, many sources of information and opportunities for problem-solving are available. The structure inherent in behavioral consultation (see discussion later) provides an opportunity to address concerns in an organized and systematic way. Clarity in goals, objectives, and procedures for assessment, intervention, and evaluation are the cornerstone of BC. Furthermore, the data-based, decision-making process allows for ongoing monitoring of intervention effects and ensures that concerns are addressed in an effective manner.

In consultation, teams of individuals work together to identify and prioritize the primary issues in need of attention and intervention. Individuals from across the child's primary contexts (i.e., school, home, health/mental health systems) together explore behavioral, medical, academic, and social-emotional issues. This joint effort allows for a greater conceptualization and understanding of the child in his/her multiple systems. Furthermore, the onus of responsibility for problem-solving is not placed on any one individual (e.g., medical staff, teacher), but rather is shared among all parties. Together, the unique knowledge and expertise brought to the consultation dialogue contribute to the identification of an appropriate plan and relevant strategies. Thus, shared ownership for problem definition and solution are promulgated through the $\mathrm{BC}$ process.

Among the problem-solving objectives of consultation is the importance of enhancing improved functioning across the multiple naturalistic settings within which a child functions. Ultimately, it is the effectiveness with which a child manages his/her behaviors at school, home, and other environments that is of primary significance. By bringing together key individuals responsible for these environments (i.e., teachers, parents, health/mental health providers), consultants promote consistent programming, systematic evaluation, and routine follow-up of interventions in natural settings. Thus, generalization and maintenance of solutions are inherent, not tangential, to consultative problem-solving.

Effective problem-solving requires unique expertise that concerns both the substantive issues of which consultation addresses, as well as the process by which concerns are identified, prioritized, and addressed. That is, effective problem-solving consultation entails content and process expertise (Welch \& Sheridan, 1995). Content expertise concerns the issues being addressed by the consultation team, such as information about a child's medical history, psychiatric disorder, or academic functioning. Evidence-based information about course, etiology, and interventions for identified disorders is an example of important content expertise necessary for effective problem-solving. Knowledge about the consultation process is also necessary for effective practice. This includes expertise in identifying concerns, exploring environmental conditions, conducting functional assessments, pooling intervention ideas, developing effective plan strategies, assessing acceptability of treatments, monitoring integrity of implementation, and evaluating outcomes of interventions. The ability to blend content and process expertise appears to be important for effective consultation (Sheridan, Kratochwill, \& Bergan, 1996; Welch \& Sheridan, 1995).

\section{Consultation as Coordination of Services}

Coordination across school, medical, and other settings provides an effective and efficient means of service delivery (U.S. Department of Education/American Educational Research Association, 1995). Virtually all serious problems are multidetermined (Schoenwald \& 
an average effect size of $1.08(S D=0.82)$, and school-based targets yielding an average effect size of $1.11(S D=1.24)$.

In school-based consultation, the social significance, acceptability, and importance of the targeted behavior and treatment plan are assessed by the consultees throughout the various phases of consultation, which likely affects treatment integrity (the extent to which the intervention is implemented as intended; Yeaton \& Sechrest, 1981) and outcome (Witt \& Elliott, 1985). These variables are related to what Wolf (1978) termed social validity, which may be defined as the subjective value judgment regarding the validation of the goals, procedures, and effects of interventions. Consultees determine social validity based on their conclusions about the goals, procedures, and outcomes of consultation. There is a need for more research investigating consumer satisfaction with and acceptability of consultation services (Sheridan, Welch, \& Orme, 1996).

To date, the primary focus of many field-based research studies has been client outcomes, with consumer satisfaction and acceptability serving as secondary variables. In one major study, Kratochwill, Elliott, and Busse (1995) measured teacher acceptability of treatments implemented in school settings using a 15-item, 6-point Likert scale. They reported relatively high scores on the measure (mean score $=80.3$; total possible score $=90$; range of individual item scores $=4.9-5.6$ ). Sheridan et al. (2001) reported multiple measures of social validity as assessed by parents and teachers. Among them, consumer perceptions regarding the acceptability of the consultation process was measured using a 15-item, 6-point Likert scale (with 6 being the highest possible rating), indicating relatively high scores for parents (average $=$ $5.44 ; S D=0.52$ ) and teachers (average $=5.45 ; S D=0.60$ ). Sheridan et al. also reported parent and teacher perceptions of treatment efficacy using a 7-item, 6-point Likert-scale instrument ( 6 being the highest possible rating). On this instrument, parents reported an average perceived efficacy score of $4.71(S D=0.95)$, and teachers reported an average perceived efficacy score of $4.30(S D=1.3)$. Whereas these studies represent meaningful contributions to the field, a review of the literature reveals that more research is clearly needed assessing data from multiple settings (e.g., home, school), multiple sources (e.g., parents, teachers), and multiple measures. Furthermore, more research is needed assessing multiple outcome indices (e.g., behavioral outcome data, consumer satisfaction data, treatment acceptability, and consultation process acceptability data) and investigating the relationship among such variables in consultation (Sheridan et al., 2001).

\section{STAGES OF BC AND CBC}

BC (Bergan \& Kratochwill, 1990) and its derivative, CBC (Sheridan, Kratochwill, \& Bergan, 1996), are comprised of four general stages (i.e., problem identification, problem analysis, treatment implementation, and treatment evaluation), three of which (i.e., problem identification, analysis, and evaluation) are operationalized via structured interviews between the consultee(s) and consultant. These stages of consultation are generally described as linear; however, in practice, $\mathrm{BC}$ is a dynamic process in which there may overlap and/or the process may become cyclical in nature to meet the individual needs of the child-client and consultation team (Bergan \& Kratochwill, 1990; Sheridan, Kratochwill, \& Bergan, 1996). The stages of BC and $\mathrm{CBC}$ are nearly identical, the primary difference being that the home system is considered in addition to the school system throughout the CBC process. Following is a discussion of each stage of $\mathrm{BC}$, including specific objectives for each progressive phase. Table 31.3 provides a summary of the stages and objectives of the model. For additional resources and interview outlines, the interested reader is referred to Kratochwill and Bergan (1990) and Sheridan, Kratochwill, \& Bergan (1996). 
TABLE 31.3

Stages and Objectives in Behavioral Consultation

I. Problem Identification

A. Define the problem(s) in behavioral terms.

B. Provide a tentative identification of antecedent, sequential, and consequent conditions that may be maintaining the behavior.

C. Provide a tentative strength of the behavior (e.g., frequency, intensity, or duration).

D. Establish a procedure for baseline data collection, including specification of what, how, and by whom it is to be recorded.

II. Problem Analysis

A. Evaluate and obtain agreement on the sufficiency and adequacy of baseline data.

B. Discuss and reach an agreement on a goal for behavior change.

C. Conduct a functional assessment (i.e., discuss antecedent, sequential, and consequent conditions of the behavior).

D. Design an intervention plan, including the specification of conditions to be changed and the practical guidelines regarding treatment implementation.

E. Reaffirm record-keeping procedures.

III. Treatment Implementation

A. Determine whether the consultee(s) have the necessary skills to implement the plan effectively, providing assistance and training as needed.

B. Monitor data collection procedures and determine whether the plan is proceeding as designed.

C. Determine whether any changes or revisions in the treatment plan are necessary.

D. Continue with data collection.

IV. Treatment Evaluation

A. Determine whether the consultation goals have been obtained.

B. Evaluate the overall effectiveness of the treatment plan.

C. Discuss strategies and tactics regarding the continuation, modification, or termination of the treatment plan.

D. Schedule additional meetings if necessary, or terminate consultation.

Note. Adapted from "Behavioral Consultation in Educational Settings," by S. M. Sheridan and T. R. Kratochwill, 1991. In J. W. Lloyd, N. N. Singh, \& A. C. Repp (Eds.), The Regular Education Initiative: Alternative Perspectives on Concepts, Issues, and Models (p. 197), Sycamore, IL: Sycamore Publishing. Copyright 1991 by Sycamore Publishing. Adapted with permission.

\section{Problem Identification}

The primary goals of the problem identification stage are to identify the most salient target concern or issue to be addressed in consultation, and to collect pretreatment data on its topography (e.g., frequency, severity) and function. Along with assessment methods (e.g., direct observation, record reviews, and behavioral rating scales), this stage includes a structured behavioral interview (Problem Identification Interview; Kratochwill \& Bergan, 1990). During the interview, the consultation team convenes to address the following objectives: (1) define the target problem(s) in behavioral terms; (2) identify tentative surrounding (i.e., antecedent, consequential, and sequential) conditions hypothesized to maintain the behavior; (3) provide a tentative strength of the behavior; (4) discuss and reach a goal for behavior change; and (5) establish a procedure for and begin baseline data collection. The baseline data collection procedures established during problem identification will continue throughout consultation to promote data-based decision making.

Target Behavior Specification. There are several factors to consider during target behavior selection and specification (Bergan \& Kratochwill, 1990; Kratochwill, 1985; Sheridan, Kratochwill, \& Bergan, 1996). Specifically, it is beneficial to narrow down behavioral clusters 
into behaviors that may be clearly operationalized and monitored (e.g., the difference between describing a child-client as "a defiant student" and describing him as "a student who fails to complete his independent seatwork, especially during math"). Additionally, it is generally more feasible to select one target behavior at a time. Behaviors that are (1) physically dangerous to the student and/or others, and/or (2) likely to result in behavior change that is maintained in an environment beyond the time of specific intervention (e.g., self-help or problem-solving skills) are often prioritized. It is desirable that the target behavior be selected and agreed on by all team members; be deemed problematic for the child-client; and be recognized as worthy of attention and expenditure of valuable resources.

During operationalization, behaviors are specified in concrete, observable, objective terms. Among many guidelines for target behavior specification, Maag (1999) recommends the stranger test (i.e., Could the target behavior definition be used by a complete stranger to monitor a specific behavior?). This test speaks to the importance of clarity and specificity in delineating the target behavior to ensure that (1) consultation members are describing and monitoring the same target behavior, and (2) independent observers who may be employed in research or practice are measuring the appropriate behaviors.

Data Collection Considerations. The development of reliable, valid data collection procedures is a critical endeavor, because data collection will continue throughout consultation, thus promoting and guiding a data-based problem-solving process (Sheridan, Cowan, \& Eagle, 2001). Data collection requires the consultation team to consider several relevant questions (Bergan \& Kratochwill, 1990): What kinds of data shall be recorded? How shall it be recorded? How long shall data collection last? Where shall it take place? The answers to the "how" and "what" questions stem in part from considering the type of concern (e.g., medical, behavioral, academic) being addressed through behavioral consultation. It is recommended that data be collected from multiple sources (e.g., parents, resource teachers, support staff), using multiple methods (e.g., behavioral checklists, permanent products), representing multiple settings (e.g., classroom, playground, home). Multi- source, method, and setting data collection provides both depth and breadth of information to assess performance and overall behavioral outcomes across settings, from the perspective of multiple individuals (Gresham \& Noell, 1993).

For school-based target behaviors that are academic in nature (e.g., reading fluency), data collection procedures typically entail curriculum-based measurement (CBM), work samples, and/or observational measures of client performance. According to Shinn (1998), CBM is "a set of standard simple, short-duration fluency measures of reading, spelling, written expression, and mathematics computation ... that measure 'vital signs' of student achievement in important areas of basic skills or literacy" (p. 1). CBM entails taking curriculum-related probes and assessing (1) the typical approach of the target student to a specific task, and (2) the types of errors being made by the student. A comparison group is achieved by assessing several "average students" within the target setting on a specific set of tasks from which a "local performance norm" is derived. The performance of the target student is then compared with this local norm sample to determine areas of relative strengths and needs.

Less complex data collection procedures include work samples and observations of student performance. Work samples are one form of "permanent products," a term frequently used in school settings that refers to items generated through the natural course of an environment that may be utilized as a means of performance assessment (e.g., homework assignments, written essays, grades, etc.). These data are among the most reliable, and are considered less taxing of time and staff resources. A less formal approach than curriculum-based assessment is the direct observation of a particular student's approach to a specific academic task. Error analyses can be conducted to ascertain the types of mistakes made or faulty algorithms used by students. Direct observation of academic tasks is similar to observations utilized for behavioral concerns 
(see section below) and may be used to monitor academic performance over time for one particular student.

For behavioral performance concerns targeted in consultation (e.g., physical aggression, off-task behavior, noncompliance), the consultation team may select from a range of data collection procedures. Event recording involves tallying or recording the number of times a specific behavior is emitted within a specific time period. In duration recording, an observer records latency, duration, or other temporal aspect of a behavior (e.g., the time it takes for a student to begin working on her math assignment). Momentary time sampling requires the observation of the occurrence or nonoccurrence of a behavior at some predetermined time (e.g., observing whether a student is pulling her hair out or biting her nails at the end of each 10-min interval). In interval recording, an observation period is broken down into discrete, equal intervals, and a behavior is recorded if it occurs at all (partial interval) or throughout (whole interval) that interval for a specified time interval (e.g., observing whether or a not a student is engaged in his classroom assignment during a 15-sec interval over the course of a 10-min period). For detailed information regarding data collection systems, the interested reader is referred to Maag (1999), Martin and Pear (1999), and Kazdin (1982). Such observation systems may provide valuable information to parents, medical experts, and others regarding the effects of a medical intervention (e.g., medication) on a child's behaviors (Northup \& Gulley, 2001).

Together, the consultant and consultees must consider the amount of time each type of data collection procedure is likely to require, and assess the cost-benefit relationship with regard to the type and quality of data likely to be yielded by each approach. They then determine which method is likely to (1) provide enough information to guide the consultation team through data-based decisions, and (2) be employed easily and reliably by the teacher or other consultee in the classroom.

\section{Problem Analysis}

Problem analysis is the second stage of $\mathrm{BC}$. The goals of problem analysis are to develop hypotheses related to the function of the target behavior and identify appropriate intervention strategies. The problem analysis stage is put into operation via a structured interview (Problem Analysis Interview, or PAI; Kratochwill \& Bergan, 1990). At the interview, the team reconvenes to achieve the following related objectives: (1) evaluate and obtain agreement on the baseline data; (2) conduct an ecological analysis of the behavior; (3) design an intervention plan, including specification of conditions to be changed and the practical guidelines regarding treatment implementation; and (4) reaffirm data collection procedures. The problem analysis stage of consultation primarily consists of two phases: the analysis phase and the plan design phase.

Analysis Phase. During the analysis phase, the team collaboratively explores setting specific antecedent, consequent, and sequential conditions surrounding the target behavior to form hypotheses about which condition(s) might be causing and/or maintaining the behavior. Antecedent conditions are events that precede the occurrence of a behavior (e.g., the student typically does not complete assignments because she becomes distracted when instructions are delivered). Setting events are antecedents that are temporally or contextually removed from the behavior (e.g., lack of adequate sleep may result in a student becoming tired and distractible at school the next day). Consequent conditions are events that result from a target behavior and may be reinforcing or punitive in nature. In a school setting, the function of undesirable behavior is often to escape a task, avoid work, gain attention from others, or attain sensory stimulation (Gresham, Watson, \& Skinner, 2001). For example, it may be the case that a student receives more reinforcement from talking with specific peers than she does through completing her classroom assignments. In this case, minimizing the peer attention (e.g., separating 
the child from her favorite peers) and allowing for interaction to occur contingent on work completion may result in increased academic engagement and work completion. Finally, sequential conditions are common patterns across problematic behaviors (e.g., a teacher may notice that the student is particularly distractible and inattentive on the Monday's immediately following weekends she spends with her father away from home). For comprehensive information regarding functional assessment and analysis, the interested reader is referred to Watson, Gresham, and Skinner (2001); O'Neill et al. (1997); and Tilly, Knoster, and Ikeda (2001).

In the analysis phase, team members are faced with the task of ascertaining whether a child's difficulties result from a skill deficit (i.e., the student lacks the requisite skills to perform a behavior or task) or a performance deficit (i.e., the child has the skill but is unable to produce a desired behavior because of environmental factors). Such analyses, when conducted appropriately, yield important treatment information, because different intervention components are utilized to address either skills deficits (e.g., skills training with modeling, with opportunities for practice and feedback) or performance deficits (e.g., environmental manipulation to preclude a specific antecedent or consequent event from causing, maintaining, or precluding a specific behavior). Information gleaned from the conditions and/or the skills analyses may be readily used by the consultation team to design a child-specific intervention plan.

Plan Design Phase. There are several variables to consider when designing an intervention to be implemented by the consultee(s). First, the plan should be based on empirically validated principles. As a scientist-practitioner, it is the consultant's responsibility to ensure that treatment components are derived from evidence-based procedures validated for similar behaviors, similar contexts, or similar functions. Second, the plan should be reasonable (i.e., not overly complex, readily applicable to the target setting), manageable, and acceptable (Sheridan, Kratochwill, \& Bergan, 1996). Treatment acceptability-defined as the judgments about treatment procedures by consumers of treatment as to whether treatment is fair, reasonable, and/or intrusive (Kazdin, 1980)-has received much attention in the consultation literature. It is generally assumed that if consultees find an intervention to be unacceptable in terms of their time, resources, or other practical and theoretical aspects, it is likely that treatment integrity (the degree to which an intervention is delivered as intended; Yeaton \& Sechrest, 1981) will suffer. Witt and Elliott (1985) hypothesize that treatment acceptability leads to treatment integrity, which in turn is directly related to consultation outcomes. Gutkin and Curtis (1999) recommend that consultants and consultees work together to design and implement plans that are acceptable in terms of criteria that are both objective (i.e., based on evidence-based practice) and subjective (i.e., is acceptable to the consultees). A review of the treatment integrity and acceptability research and practice literature is beyond the scope of this chapter. The interested reader is referred to Gresham $(1989,1996)$ for a thorough discussion regarding how to monitor and improve treatment integrity, and Eckert and Hintze (2000) for a review of the treatment acceptability literature.

\section{Treatment Implementation}

During this stage of $\mathrm{BC}$, the consultee(s) implements the treatment plan developed through the functional assessment and PAI. Although there is no structured meeting associated with this stage of consultation, the consultation team remains in constant contact to monitor treatment integrity, assess any unintentional side effects, and assess the initial efficacy of the treatment plan. The primary objective of this stage of consultation is to maximize the likelihood that the plan will produce the desired effects (Sheridan, Kratochwill, \& Bergan, 1996). During intervention implementation, the consultant is advised to remain in constant contact with consultees to: (1) monitor their needs; (2) provide sufficient knowledge and support; (3) reinforce their efforts in plan implementation; and (4) monitor and guide them should an alteration to 
the plan be necessary. More complex interventions may require additional supports (i.e., additional staff) and/or individualized consultee training (i.e., providing education, modeling, and allowing the consultees to practice before intervention; Gutkin \& Curtis, 1999) to maximize treatment integrity and outcome.

\section{Treatment Evaluation}

The goals of treatment evaluation are to evaluate the data collected over the course of consultation (i.e., baseline, treatment implementation), determine if consultation goals have been attained, and assess the need for modification or continuation of the treatment plan. A structured interview (the Treatment Evaluation Interview; TEI; Kratochwill \& Bergan, 1990) is associated with this stage. The specific objectives of this interview are to: (1) evaluate treatment data to determine whether the goals of consultation have been met; (2) evaluate the overall effectiveness of the treatment plan; (3) discuss strategies and tactics regarding the continuation, modification, or termination of the treatment plan; and (4) discuss strategies for maintenance and generalization of the treatment gains. This stage of consultation assesses whether the hypotheses generated through data analysis were valid, and evaluates whether or not the plan responded to those conditions hypothesized to maintain the target behavior.

Like all stages of consultation, treatment evaluation is a process unique to the needs of the child-client and team members. Treatment evaluation may entail one meeting, one meeting plus telephone contact(s), or several meetings spread out over time until a mutually determined set of consultation and behavioral goals are met. In cases where no progress is made, the consultation team may recycle through the consultation process to more thoroughly analyze the target behavior, and develop an alternative treatment plan based on either a significant alteration of the original plan or another hypothesis regarding the cause for the behavior. In cases where some progress has been made, yet behavioral goals were not completely met, the consultation team may opt to make minor adjustments to the plan to maximize the potential for success (e.g., adjust the dosage or schedule of a medication, change the available reinforcer items to maintain motivation and progress). In cases where the goal has been met, the team may either (1) continue with implementation as is, or (2) discuss specific strategies for maintenance (e.g., increasing the behavioral goal required for reinforcement, gradually fading the intervention) and generalization (e.g., transferring the intervention procedures to a setting not originally targeted for intervention). Regardless of the next step in the consultation process, it should be a collaborative decision, with all team members across settings supporting and assisting one another until termination is mutually determined.

\section{CONSULTATION WITHIN THE SCHOOL CONTEXT}

Problem-solving in consultation entails more than identifying a target concern and implementing chosen interventions. Contextual features of applied consultation and intervention (e.g., interpersonal climate, adult/peer relations, expectations for staff and students, values among service providers) are some of the intangible aspects of service delivery worthy of consideration. Furthermore, consideration of a school's culture and entry into the school system invokes important considerations.

\section{School Culture}

A school's culture is a pool of information related to virtually every aspect of its environment. It includes the importance value placed on various activities, expected procedures of operation, and appropriate behaviors among individuals within the school environment. 
Culture is comprised of a set of variables that include attitudes, values, norms, beliefs, role expectations, and customs that are transmitted to group members (Gollnick \& Chinn, 1990). It influences how an individual in that setting thinks, feels, and behaves; it serves to maintain stability in that environment and is often difficult to alter by individuals within or external to the system (Welch \& Sheridan, 1995). The culture of a school is essential to understand as it permeates the beliefs, expectations, and experiences of teachers and administrators. Problemsolving strategies or instructional or behavioral modifications for an individual student may be perceived as unrealistic or inappropriate, depending on the degree to which they fit within the norms of the particular school environment.

Consulting in school settings presents unique challenges because of the systemic and organizataional features of schools in general. Historically, one of the most salient barriers to consultation in school settings and among school personnel has been the organizational issue of lack of time (Idol-Maestas \& Ritter, 1985). Teachers are responsible for delivering instruction in their classrooms for several consecutive hours per day, often with little time away from students or only brief periods dedicated for planning. Teachers' work is defined by the time spent with students, and whole group instruction is the primary instructional format (Elmore, 1987). Other pragmatic difficulties encountered in school settings include large caseloads and classrooms, scheduling problems, and competing and overwhelming responsibilities. Such issues are of paramount importance when considering the nature and complexity of requests made of teachers. As already reviewed, the time required for implementation and complexity of an intervention influence its acceptability by treatment agents, which may affect the degree to which it is delivered in the natural setting (cf. Witt \& Elliott, 1985).

\section{Entry Considerations}

Some of the aforementioned concerns about school systems and cultural and contextual features therein can be addressed through appropriate entry practices. Entry refers to "the consultant's crossing of organizational boundaries into a system or work setting" (Brown et al., 1995, p. 107). Two distinct aspects of entry are relevant. Formal entry requires consultants to gain sanction for consultation activities by persons in administrative or authority positions within the setting (e.g., school principals). There are also informal aspects of entry, requiring consultants' activities and roles to be accepted by consultees (e.g., teachers, other school personnel, parents).

Several authors have discussed issues surrounding formal entry extensively (e.g., Conoley \& Conoley, 1992; Dougherty, 2000; Gallesich, 1982). The processes surrounding entry are critical to the success of consultation and should not be underestimated. Dougherty (2000) identified four phases of entry, including exploring needs, contracting, physically entering the setting, and psychologically entering the setting. A formal discussion of expectations regarding roles (for the consultant, consultees, and system/organization) and activities (including active involvement, information-sharing, data collection, and evaluation) is essential. A verbal or written contract is often useful as it outlines specific details of the relationship, including fees, responsibilities, time limits, accepted activities, issues of confidentiality, and other parameters of consultation (Conoley \& Conoley, 1992).

Informal acceptance of consultation services is perhaps the most critical feature of the relationship. During the time that consultants and consultees begin their working relationship, issues of trust, cooperation, or reluctance to share information may be salient (Gallesich, 1982). The transition from formal entry to informal acceptance is a normal and expected process, because it affords consultees opportunities to evaluate the consultant's skills and operating style, and to assess possible risks of consultation. Because consultees participate voluntarily and may or may not be committed to a long-term consultative relationship, the effective consultant begins relationship-building early on in the consultation process by establishing 
trust, rapport, and a shared perspective of the nature of the consultation process (a process similar to, but not the same as, the therapist-client relationship). Furthermore, Gutkin and Curtis (1999) recommend that the school consultant: (1) maintain professional confidence with regard to both the consultees and the child-client; (2) encourage and reinforce active consultee participation; and (3) actively support the consultee(s) throughout the consultation process. Without consultee support, consultation is not possible; effective entry is achieved when the consultant takes the time to establish rapport, demonstrate respect, and build mutual trust. Challenges associated with informal acceptance also may be minimized through ongoing interaction, contact, and opportunities to develop an interpersonal connection outside of the consultation interaction.

Brown et al. (1995) summarize the issues surrounding the critical entry stage aptly: "Entry ... is not a single step, but an ongoing process that has both formal and informal components. Successful entry is characterized by a progressively deeper understanding of the organization on the part of the consultant, increased trust and acceptance of the consultant by members of the consultee organizations, and a clear, mutual understanding of the objectives, methods, and procedural details of consultation by both parties" (p. 111).

\section{CONCLUSIONS}

School-based consultation is a vehicle through which consultants (i.e., medical professionals, psychologists) can work together with parents and educators to promote cross-setting information-sharing, problem-solving, and coordination of services. The use of consultation in schools can achieve several goals, including (1) the short-term goal of resolving the student's presenting difficulties (i.e., remedial intervention), and (2) the long-term goals of preventing future similar challenges and improving the consultees' problem-solving skills (i.e., a preventive approach). The purpose of this chapter is to provide an impetus for professionals in various pediatric settings to utilize this service-delivery model within schools.

By considering consultation through the lens of ecological theory, the importance of relationships among the significant adults in a child's life is evident. Evidence-based, structured consultation procedures provide a technology by which these key adults (e.g., pediatric specialists, parents, teachers) can come together to share information and expertise, address presenting concerns, and coordinate services for children and families. By recognizing and understanding unique issues presented in school contexts and engaging in important entry practices, consultants can be positioned to offer important and effective indirect services in the natural settings within which their clients function.

\section{ACKNOWLEDGMENTS}

Preparation of this chapter was supported in part by Grants 325H980126 and 325D990010 awarded to the first author by the U.S. Department of Education, Office of Special Education and Rehabilitative Services. The opinions expressed herein belong to the authors and do not reflect those of the granting agency.

\section{REFERENCES}

Bergan, J. R., \& Kratochwill, T. R. (1990). Behavioral consultation and therapy. New York: Plenum.

Bramlett, R. K., \& Murphy, J. J. (1998). School psychology perspectives on consultation: Key contributions to the field. Journal of Educational and Psychological Consultation, 9, 29-55. 
Bronfenbrenner, U. (1977). Toward an experimental ecology of human development. American Psychologist, 32, 513-529.

Brown, D., Pryzwansky, W. B., \& Schulte, A. C. (1995). Psychological consultation: Introduction to theory and practice (3rd ed.). Boston: Allyn and Bacon.

Caplan, G. (1970). The theory and practice of mental health consultation. New York: Basic Books.

Christenson, S. L., \& Sheridan, S. M. (2001). Schools and families: Creating essential connections for learning. New York: Guilford Press.

Cohen, J. (1992). A power primer. Psychological Bulletin, 112, 155-159.

Colton D. L., \& Sheridan, S. M. (1998). Conjoint behavioral consultation and social skills training: Enhancing the play behaviors of boys with attention deficit hyperactivity disorder. Journal of Educational and Psychological Consultation, 9, 3-28.

Conoley, J. C. (1987). Schools and families: Theoretical and practical bridges. Professional School Psychology, 2 , 191-203.

Conoley, J. C., \& Conoley, C. W. (1992). School consultation practice and training (2nd ed.). Boston: Allyn and Bacon.

Dougherty, A. M. (2000). Psychological consultation and collaboration in school and community settings (3rd ed.). Belmont, CA: Wadsworth/Thomson Learning.

Eckert, T. L., \& Hintze, J. M. (2000). Behavioral conceptualizations and applications of treatment acceptability: Issues related to service delivery and research methodology. School Psychology Quarterly, 15, 123-148.

Elmore, R. F. (1987). Reform and the culture of authority in schools. Educational Administration Quarterly, 23(4), 60-78.

Gallesich, J. (1982). The profession and practice of consultation. San Francisco: Jossey Bass.

Galloway, J., \& Sheridan, S. M. (1994). Implementing scientific practices through case studies: Examples using home-school interventions and consultation. Journal of School Psychology, 32, 385-413.

Gollnick, D. M., \& Chinn, P. C. (1990). Multicultural education in a pluralistic society (3rd ed.), Columbus, $\mathrm{OH}$ : Merrill.

Gresham, F. M. (1989). Assessment of treatment integrity in school consultation and prereferral intervention. School Psychology Review, 18, 37-50.

Gresham, F. M. (1996). Treatment integrity in single-subject research. In R. D. Franklin, D. B. Allison, \& B. S. Gorman (Eds.), Design and analysis of single-case research (pp. 93-117). Mahweh, NJ: Lawrence Erlbaum.

Gresham, F. M., \& Noell, G. H. (1993). Documenting the effectiveness of consultation outcomes. In J. E. Zins \& T. R. Kratochwill (Eds.), Handbook of consultation services for children: Applications in educational and clinical settings (pp. 249-273). San Francisco, CA: Jossey-Bass.

Gresham, F. M., Watson, T. S., \& Skinner, C. H. (2001). Functional behavioral assessment: Principles, procedures, and future directions. School Psychology Review, 30, 156-172.

Gutkin, T. B., \& Conoley, J. C. (1990). Reconceptualizing school psychology from a service delivery perspective: Implications for practice, training, and research. Journal of School Psychology, 28, 203-223.

Gutkin, T. B., \& Curtis, M. (1999). School based consultation theory and practice: The art and science of indirect service delivery. In C. R. Reynolds \& T. B. Gutkin (Eds.), Handbook of school psychology (3rd ed., pp. 598-637). New York: Wiley.

Hansen, D. A. (1986). Family-school articulations: The effects of interaction rule mismatch. American Educational Research Journal, 23, 643-659.

Henggeler, S. W. (1991). Multidimensional causal models of delinquent behavior. In R. Cohen \& Y. A. Siegel (Eds.), Context and development (pp. 211-231). Hillsdale, NJ: Lawrence Erlbaum.

Idol-Maestas, L., \& Ritter, S. (1985). A follow-up study of resource/consulting teachers: Factors that facilitate and inhibit teacher consultation. Teacher Education and Special Education, 8, 121-131.

Kazdin, A. E. (1980). Acceptability of alternative treatments for deviant child behavior. Journal of Applied Behavior Analysis, 13, 259-273.

Kazdin, A. E. (1982). Single-case research designs: Methods for clinical and applied settings. New York: Oxford University Press.

Kratochwill, T. R. (1985). Case study research in school psychology. School Psychology Review, 14, $204-215$.

Kratochwill, T. R., \& Bergan, J. R. (1990). Behavioral consultation in applied settings: An individual guide. New York: Plenum.

Kratochwill, T. R., Elliott, S. N., \& Busse, R. T. (1995). Behavioral consultation: A five-year evaluation of consultant and client outcomes. School Psychology Quarterly, 10, 87-117.

Maag, J. W. (1999). Behavior management: From theoretical implications to practical applications. San Diego, CA: Singular Publications.

Maher, C. A., Illback, R. J., \& Zins, J. E. (1984). Organizational psychology in the schools: A handbook for professionals. Springfield, IL: Thomas. 
Martin, G., \& Pear, J. (1999). Behavior modification: What it is and how to do it. Upper Saddle River, NJ: Prentice Hall.

Medway, F. J. (1979). How effective is school consultation: A review of recent research. Journal of School Psychology, $17,275-282$.

Medway, F. J., \& Updyke, J. F. (1985). Meta-analysis of consultation outcome studies. American Journal of Community Psychology, 13, 489-504.

Neill, T. K. (1997). Integrating services for children with severe emotional disabilities through coordination. In R. J. Illback, C. T. Cobb, \& H. M. Joseph (Eds.), Integrated services for children and families: Opportunities for psychological practice (pp. 157-190). New York: APA Books.

Northup, J., \& Gulley, V. (2001). Some contributions of functional analysis to the assessment of behaviors associated with attention deficit hyperactivity disorder and the effects of stimulant medication. School Psychology Review, 30, $227-238$.

O'Neill, R. E., Horner, R. H., Albin, R. W., Sprague, J. R., Storey, K., \& Newton, J. S. (1997). Functional assessment and program development for problem behavior: A practical handbook (2nd ed.). Pacific Grove, CA: Brooks/Cole.

Ray, K. P. \& Watson, T. S. (2001). Analysis of the effects of temporally distant events on school behavior. School Psychology Quarterly, 16, 324-342.

Reinking, R. J., Livesay, G., \& Kohl, M. (1978). The effects of consultation style on consultee productivity. American Journal of Community Psychology, 6, 283-290.

Schoenwald, S. K., \& Henggeler, S. W. (1997). Combining effective treatment strategies with family-preservation models of service delivery. In R. J. Illback, C. T. Cobb, \& H. M. Joseph (Eds.), Integrated services for children and families: Opportunities for psychological practice (pp. 121-136). New York: APA Books.

Sheridan, S. M. (1997). Conceptual and empirical bases of conjoint behavioral consultation. School Psychology Quarterly, 12, 119-133.

Sheridan, S. M., Cowan, R. J., \& Eagle, J. W. (2001). Partnering with parents in educational programming for students with special needs. In C. F. Telzrow \& M. Tankersley (Eds.), IDEA amendments of 1997: Practice guidelines for school-based teams (pp. 307-350). Bethesda, MD: National Association of School Psychologists.

Sheridan, S. M., Eagle, J. W., Cowan, R. J., \& Michelson, W. (2001). The effects of conjoint behavioral consultation in inclusionary settings: Results of a four-year investigation. Journal of School Psychology, 39, 361-385.

Sheridan, S. M., \& Gutkin, T. B. (2000). The ecology of school psychology: Examining and changing out paradigm for the 21st century. School Psychology Review, 29, 485-502.

Sheridan, S. M., \& Kratochwill, T. R. (1991). Behavioral consultation in educational settings. In J. W. Lloyd, A. C. Repp, \& N. N. Singh (Eds.), The regular education initiative: Alternative perspectives on concepts, issues, and methods (pp. 193-210). Sycamore, IL: Sycamore Publishing Co.

Sheridan, S. M., Kratochwill, T. R., \& Bergan, J. R. (1996). Conjoint behavioral consultation: A procedural manual. New York: Plenum.

Sheridan, S. M., Kratochwill, T. R., \& Elliott, S. N. (1990). Behavioral consultation with parents and teachers: Delivering treatment for socially withdrawn children at home and school. School Psychology Review, 19, 33-52.

Sheridan, S. M., Welch, M., \& Orme, S. (1996). Is consultation effective? A review of outcome research. Remedial and Special Education, 17, 341-354.

Shinn, M. R. (Ed.). (1998). Advanced applications of curriculum-based measurement. New York: Guilford.

Tilly W. D., III, Knoster, T. P., \& Ikeda, M. J. (2001). Functional behavioral assessment: Strategies for positive behavior support. In C. F. Telzrow \& M. Tankersley (Eds.), IDEA amendments of 1997: Practice guidelines for school-based teams (pp. 151-198). Bethesda, MD: National Association of School Psychologists.

U.S. Department of Education/American Educational Research Association (1995). School-linked comprehensive services for children and families: What we know and what we need to know. Washington, DC: Author.

Watson, T. S., Gresham, F. M., \& Skinner, C. (Guest Eds.). (2001). Issues and procedures for implementing functional behavior assessments in schools [Special issue]. School Psychology Review, 30(2), 153-304.

Weiner, R. K., Sheridan, S. M., \& Jenson, W. R. (1998). The effects of conjoint behavioral consultation and a structured homework program on math completion and accuracy in junior high school students. School Psychology Quarterly, 13, 281-309.

Welch, M., \& Sheridan, S. M. (1995). Educational partnerships: Serving students at risk. San Antonio, TX: Harcourt Brace.

Witt, J. C., \& Elliott, S. N. (1985). Acceptability of classroom intervention strategies. In T. R. Kratochwill (Ed.), Advances in school psychology (Vol. 4, pp. 251-288). Hillsdale, NJ: Lawrence Erlbaum.

Witt, J. E., Martens, B. K., \& Elliott, S. N. (1984). Assessing the acceptability of behavioral interventions used in classrooms. Psychology in the Schools, 20,510-517.

Wolf, M. M. (1978). Social validity: The case for subjective measurement or how applied behavior analysis is finding its heart. Joumal of Applied Behavior Analysis, 11, 203-214.

Yeaton, W. H., \& Sechrest, L. (1981). Critical dimensions in the choice and maintenance of successful treatment: Strength, integrity, and effectiveness. Journal of Consulting and Clinical Psychology, 49, 156-167. 